
\title{
КРИМИНАЛИСТИЧЕСКИЕ АСПЕКТЫ ПРИМЕНЕНИЯ МЕР ПРЕСЕЧЕНИЯ В РАМКАХ РАССЛЕДОВАНИЯ УГОЛОВНЫХ ДЕЛ
}

\section{FORENSIC ASPECTS OF THE USE OF PREVENTIVE MEASURES IN THE INVESTIGATION OF CRIMINAL CASES \\ V. Akhmetgaleev}

Summary: The article analyzes the Russian criminal procedure legislation regulating the selection of preventive measures, reveals the reasons for the use of preventive measures, factors, circumstances and conditions that affect the use of a particular measure of procedural coercion, highlights the stages of the decision-making process on the use of preventive measures in the investigation of a criminal case and the mechanism for their application. The author reveals the criminalistic essence of the use of preventive measures in the investigation of criminal cases and their criminalistic significance, aimed at solving crimes, «saving» the existing evidence base and obtaining new information of particular interest to the investigator. Based on the systematization and analysis of the use of preventive measures in the investigation of criminal cases, the author, in the prism of criminalistics, proposed definitions of the concepts: "preventive measures» and «application of preventive measures».

Keywords: investigator, preliminary investigation, investigator's activity, criminalistics, criminalistic aspect, criminalistic essence, preventive measures, application of preventive measures, grounds for applying preventive measures.
$\mathrm{B}$ науке институт мер пресечения представляет собой реализуемый в рамках уголовного процесса, применяемый в соответствующих условиях и в определенном уголовно-процессуальным законодательством порядке способ воздействия уполномоченных на то Уголовно-процессуальным кодексом Российской Федерации (далее - УПК РФ) должностных лиц на уровень свободы обвиняемых (подозреваемых) при расследовании уголовных дел.

Стоит особо отметить тот факт, что применение в ходе предварительного расследования мер пресечения, закрепленных в главе 13 УПК РФ и составляющих наиболее значительную и действенную часть мер уголовнопроцессуального принуждения, всегда связано с реальным ущемлением прав и свобод объектов принуждения. С.Н. Кожевников определяет принуждение как определенный метод воздействия, обеспечивающий, вопреки воли человека, совершение последним действий в интересах субъекта принуждения. При этом, необходимость применения подобного метода воздействия наступает в случае возникновения противоречивых устремлений
Ахметгалеев Вадим Ралифович

капитан юстиции, старший следователь, отдел МВД России по Мишкинскому району; адъюнкт, Уфимский ЮИ МВД России vahmetgaleev@yandex.ru

Аннотация: В статье проводится анализ Российского уголовно-процессуального законодательства, регламентирующего избрание мер пресечения, раскрываются основания применения мер пресечения, факторы, обстоятельства и условия, влияющие на применение той или иной меры процессуального принуждения, выделены стадии процесса принятия решения о применении мер пресечения в рамках расследования уголовного дела и механизм их применения. Автор раскрывает криминалистическую сущность применения мер пресечения в рамках расследования уголовных дел и их криминалистическое значение, направленное на раскрытие преступлений, «сбережение» имеющейся доказательственной базы и получение новой, представляющей определенный интерес для следователя, информации. На основе систематизации и анализа применения мер пресечения в рамках расследования уголовных дел, автором, в призме криминалистики, предложены определения понятий: «меры пресечения» и «применение мер пресечения».

Ключевые слова: следователь, предварительное расследование, деятельность следователя, криминалистика, криминалистический аспект, криминалистическая сущность, меры пресечения, применение мер пресечения, основания применения мер пресечения.

субъектов, где одним из субъектов предписывается необходимость выполнения определенных требований иным субъектом. Посредством применения данного метода воздействия возможно подавить противоречащие общественной воле мотивы поступков человека, ограничить свободу действий индивида, стимулировать необходимое желательное субъекту принуждения поведение [6, 48]. Вопреки утверждениям отдельных ученых [13, 49], мерам пресечения присущ признак принудительности вне зависимости от соответствия их применения интересам и волеизъявлению обвиняемых (подозреваемых). Исходя из этого, следует заключить, что применение практически каждой меры уголовнопроцессуального принуждения влечет определенное ограничение прав и свобод объекта принуждения [1, 25] (свободы воли и неприкосновенности (ст.22 Конституции РФ), свободы передвижения (ст.27 Конституции РФ)).

Учитывая тот факт, что меры пресечения в рамках расследуемого уголовного дела применяются к лицам, которые еще не признаны виновными в совершении преступлений, то применение данных мер должно быть 
обоснованным, необходимым, иметь соразмерный и исключительный характер исходя из обстоятельств конкретного уголовного дела, и, в то же время, должны способствовать раскрытию преступления. Применение мер пресечения, если это не противоречит интересам иных лиц и охраны общественной безопасности, должно обеспечивать достижение своей цели с возможно наименьшим лишением либо ограничением прав обвиняемого (подозреваемого). В подтверждении сказанному, следует отметить, что общепризнанные нормы международного права, наряду с Конституцией РФ, «допускают возможность ограничения права на свободу лишь в той мере, в какой оно необходимо в определенных законом целях» [12]. Вместе с тем, положения ст.52 Хартии основных прав Европейского Союза от 07.12.2000 года, конкретизируют данное положение, указывая, что любое ограничение не должно идти дальше поставленных перед ним целей [5, 146-147].

Заметим, что вопрос о применении каждой конкретной меры пресечения, с учетом особенностей ее применения, выбор которой должен быть основан в соответствии с целями, установленными УПК РФ и подтвержденными материалами уголовного дела, тесно связан с личностью каждого отдельно взятого обвиняемого (подозреваемого), вида совершенного им преступления, а также, в целом, следственной ситуации, сложившейся в ходе расследования конкретного уголовного дела. Тем самым, применение мер пресечения содержит в себе признак индивидуализации, обеспечивающий законное и обоснованное ограничение прав личности (ст.7 УПК РФ) и выступает своеобразным регулятором правильного избрания и применения определенной меры пресечения. При применении мер пресечения, субъект принуждения (судья, следователь или дознаватель), в совокупности с интуицией, должен основываться на фактических данных, указывающих на вероятность недобросовестности объекта принуждения, что даст возможность принять законное и обоснованное решение о выборе той или иной меры пресечения в отношении конкретного обвиняемого (подозреваемого) и способствовать раскрытию расследуемого преступления, установив необходимое органу расследования модель поведения лица. Говоря о таком понятии как «обоснованность», следует подчеркнуть, что ключевыми элементами обоснованного решения должны являться не только фактические обстоятельства, установленные в рамках расследования, которые свидетельствуют о наличии оснований, связанных с возможностью принятия данного решения [3, 119], но и основанные на фактических данных предположения.

В ч.1 ст.97 УПК РФ законодатель определяет, что следователь, дознаватель или суд, в пределах предоставленных им полномочий, в том числе, с целью реализации криминалистических задач при расследовании уголовного дела, имеют право избрать в отношении обвиняемого (подозреваемого) одну из, предусмотренных УПК РФ, мер пресечения, при наличии достаточных оснований полагать, что обвиняемый (подозреваемый):

1. скроется от дознания или предварительного следствия;

2. может продолжить заниматься преступной деятельностью;

3. может угрожать свидетелю, а также иным участникам уголовного судопроизводства, а также уничтожить доказательства либо иным путем воспрепятствовать производству по уголовному делу.

Перечень оснований для избрания мер пресечения является исчерпывающим и данные основания едины для избрания любой меры пресечения. Анализируя данную норму, мы видим, что законодатель устанавливает основания мер пресечения независимо от степени тяжести совершенного обвиняемым (подозреваемым) преступления.

Законодателем отмечено, что в качестве оснований применения мер пресечения могут выступать достаточные данные, которые свидетельствуют о возможности совершения обвиняемым (подозреваемым) действий, предусмотренных ч.1 ст.97 УПК РФ. Но что считать «достаточными данными»? Так, в практической деятельности, «достаточные данные» зачастую сопоставляют с установленными, в рамках предварительного расследования, фактическими данными (о чем утверждают 52,9 \% проанкетированных практических работников) либо с вероятными данными, исходя из полученной информации в ходе расследования (о чем утверждают 47,1 \% проанкетированных практических работников). Также, вышеуказанное понятие связывают с информацией, полученной в рамках оперативно-разыскной деятельности или из иных внешних источников (телевидение, интернет, газеты, журналы, предоставление «доброжелателем» проверенных следствием или судом данных, характеризующих личность обвиняемого (подозреваемого), устанавливающих круг его общения, сферы преступной деятельности, а также данные, подтверждающие факты планируемого возможного сокрытия от следствия или суда, данные, подтверждающие факт уничтожения вещественных доказательств, либо угроз иным участникам уголовного судопроизводства).

По нашему мнению, к достаточным данным, учитываемым при выборе определенной меры пресечения, необходимо относить совокупность фактических, вероятных и, полученных в рамках оперативно-разыскной деятельности и иных внешних источников, данных, т.к. только совокупность наиболее полной информации об обвиняемом (подозреваемом), даст, без чрезмерного ограничения прав и свобод последнего, соответствующий результат в рамках криминалистической деятель- 
ности при применении мер пресечения, что повлияет на повышение качества расследования уголовных дел в целом.

Рассматривая понятие «основание», стоит отметить, что Л.В. Тихомирова и М.Ю. Тихомиров под понятием «основание» понимают «совокупность законодательно предусмотренных обстоятельств, фактов, условий и предпосылок, которые обеспечивают наступление юридических последствий» [14, 552]. В уголовно-процессуальном аспекте, применительно к мерам пресечения, под понятием «основание» необходимо понимать совокупность достаточных и подтверждающих возможное наступление, указанных в законе событий, данных. Исходя из вышеизложенного, следует определить, что основаниями применения мер пресечения на досудебной стадии являются связанные со свойствами лица, выражающимися в поступках и действиях, обстоятельства.

Рассматривая основания применения мер пресечения, следует упомянуть, что они подразделяются на общие, то есть основания, которые формируют убеждение следователя о применении мер пресечения в связи с наличием фактических обстоятельств, указанных в ч.1 ст.97 УПК РФ (при их наличии применение любой мер пресечения возможно по любому составу преступления) и специальные-обстоятельства, которые дают возможность выбора конкретной меры пресечения (например: в целях предотвращения возможности обвиняемого (подозреваемого) скрыться, в основу берется тяжесть совершенного преступления). Таким образом, наряду с общими, специальные основания, устанавливающие обстоятельства, дозволяющие выбор отдельной меры пресечения, оказывают главенствующее значение при выборе той или иной меры пресечения в отношении объекта принуждения. Например, невозможно применить меру пресечения в виде залога в отсутствии согласия объекта принуждения [2, 79], также невозможно применить меру пресечения в виде наблюдения командования воинской части в отношении лица, не имеющего статус военнослужащего [10, 148].

Вместе с тем, специальные основания подлежат отграничению от учитываемых при применении мер пресечения обстоятельств, предусмотренных ст. 99 УПК РФ, а именно: тяжесть совершенного лицом преступления, сведения о личности обвиняемого (подозреваемого), возраст объекта принуждения, его состояние здоровья, семейное положение, род его занятий, а также другие обстоятельства. Так, В.М. Корнуков отмечает, что «данные, служащие достаточными основаниями для применения мер пресечения, как правило, позволяют сделать лишь вероятностный, а не достоверный вывод, а обстоятельства, указанные в ст.91 УПК (ст.99 УПК РФ - прим. автора), дают возможность лишь правильно определить степень вероятности совершения обвиняемым (подо- зреваемым) действий, с целью предотвращения которых применяются меры пресечения» $[9,56]$. П.М. Давыдов и П.П. Якимов, поддерживая данную точку зрения, отмечают, что обстоятельства, указанные в ст.99 УПК РФ «не могут служить причиной избрания той или иной меры пресечения, на основании оценки данных обстоятельств можно лишь предполагать о будущем поведении обвиняемого (подозреваемого)» [4, 16].

Однако, в последнее время остро ставится вопрос о проблеме обосновывания на досудебном этапе уголовного судопроизводства фактических обстоятельств при принятии решения о применении мер пресечения, что указывает на отсутствие полноценной концепции, направленной на их доказывание [8, 110-111]. Законодатель определяет в ч.1 ст.97 УПК РФ риски, которые, по своей сути, должны давать основания полагать, что обвиняемый (подозреваемый) может вести себя в рамках уголовного судопроизводства неподобающим образом, в связи с чем, в данном случае, следует вести речь об обосновании наличия подозрения в данном неподобающем поведении. Указанное подозрение субъекта принуждения, учитывая сведения о совершенном лицом преступлении, соотношении возможных сроков предварительного расследования и сроков применения возможных мер пресечения, должно основываться, кроме того, и на фактических данных, предоставляющих возможность достоверно спрогнозировать в будущем поведение обвиняемого (подозреваемого) $[7,106]$ в процессе расследования уголовного дела. Вместе с тем, не стоит забывать и об условиях, без которых применение меры пресечения невозможно, а именно:

1. наличие возбужденного уголовного дела;

2. наличие лица в процессуальном статусе обвиняемого (подозреваемого).

Таким образом, процесс принятия решения о выборе конкретной меры пресечения следователем или судом должен проходить через следующие стадии:

1. осознание следственной ситуации по уголовному делу исходя из имеющихся материалов уголовного дела;

2. осознание поведения обвиняемого (подозреваемого), его характера, предпринимаемых им действий, а также полноты и достоверности даваемых им показаний в рамках расследования уголовного дела, сбор характеризующего материала на обвиняемого (подозреваемого) с осмыслением полученных в отношении лица характеристик, факта возмещения последним причиненного ущерба;

3. установление факта совершения либо осознание, исходя из материалов уголовного дела, изучения личности обвиняемого (подозреваемого) и его характеристик, возможного совершения им действий, указанных в ч.1 ст.97 УПК РФ;

4. принятие решения о применении конкретной 
меры пресечения в отношении обвиняемого (подозреваемого) либо замена ранее избранной меры пресечения на более строгую меру пресечения;

5. вынесение процессуального документа, регламентирующего решение о применении конкретной меры пресечения;

6. исполнение меры пресечения. То есть, при рассмотрении вопроса о применении меры пресечения, уполномоченное на то процессуальное лицо, устанавливая наряду с общими основаниями, ряд специальных оснований, учитывая также при этом обстоятельства, закрепленные в ст.99 УПК РФ, принимает решение о применении в отношении обвиняемого (подозреваемого) конкретной меры пресечения, в рамках исполнения которой возможно проработать тактические приемы, комбинации и операции, направленные на раскрытие преступления.

Следует также отметить, что в настоящее время, указанные в ч.1 ст.97 УПК РФ, общие основания фактически воспринимаются как специальные основания, что порождает неизбежность «избрания» мер пресечения в отношении любого обвиняемого (подозреваемого), что, при соответствующей модели поведения последнего, может породить негативные для предварительного расследования моменты.

Необходимо упомянуть, что несвоевременное применение мер пресечения, либо их неприменение вовсе, может привести к довольно серьезным отрицательным последствиям, которые могут свести результаты борьбы с преступностью на нет. Просчеты следователя или суда в выборе и применении мер пресечения могут привести к совершению объектом принуждения иных, зачастую, более тяжких преступлений, уклонению от явок к следователю, уничтожению или сокрытию вещественных доказательств, негативному, порой, через угрозы, воздействию на иных участников уголовного судопроизводства, что, в конечном счёте, окажет существенное влияние на раскрываемость преступлений. В.А. Михайлов, рассматривая организационно-управленческий аспект мер пресечения, взяв за основу учение Р.С. Белкина о 4-х уровнях управления в сфере борьбы с преступностью, отмечал, что «на пер- вом уровне решаются задачи законодательного обеспечения мер пресечения, на втором уровне - задачи обеспечения их применения, на третьем - обеспечения законности и обоснованности их применения в рамках криминалистической методики, на четвертом - задачи тактики применения отдельных мер пресечения к отдельным обвиняемым (подозреваемым), а также процессуального порядка их применения» $[11,11]$.

Учитывая, что криминалистический аспект применения мер пресечения тесно взаимосвязан с их криминалистическим обеспечением, то задачи криминалистики, при применении мер пресечения, будут заключаться в разработке комбинаций, операций и приемов применения научных положений в области криминалистической тактики и методики обосновывания применения мер пресечения в отношении обвиняемых (подозреваемых) на досудебной стадии, предупреждению их преступной деятельности и противоправного поведения, включая и разработку тактических комбинаций по розыску и задержанию обвиняемых (подозреваемых).

Таким образом, анализируя вышеизложенное, мы приходим к выводу, что мерами пресечения, в криминалистическом аспекте, будут являться меры процессуального принуждения, применяемые в рамках уголовного судопроизводства в отношении обвиняемого (подозреваемого) на основаниях и в пределах, предусмотренных уголовно-процессуальным законом следователем, дознавателем или судом, направленные на раскрытие преступления, установление обстоятельств, подлежащих доказыванию (ст. 73 УПК РФ) по уголовному делу, изобличение виновных лиц и обеспечение их надлежащего поведения.

Применением мер пресечения, в криминалистическом аспекте, будет являться основанный на анализе сложившейся в рамках уголовного дела следственной ситуации, проверенных версиях и планирования расследования, а также данных о личности обвиняемого (подозреваемого) и его характеристик, интеллектуальный волевой акт следователя, приводящий к выбору наиболее оптимального вида меры пресечения, основанного на требованиях УПК РФ с учетом решения конкретной тактической задачи исходя из создавшейся следственной ситуации.

\section{ЛИТЕРАТУРА}

1. Белоусов А.Е. Вопросы теории и практики применения мер уголовно-процессуального пресечения по законодательству Российской Федерации: дис. ... канд. юрид. наук. Ижевск. 1995. 145 с.

2. Вершинина С.И. Проблемы правового регулирования залога как меры пресечения // Юридическая наука и практика: Вестник Нижегородской академии МВД России. 2019. №2. С. 78-83.

3. Гаприндашвили Р.Т. Классификация уголовно-процессуальных решений // Вестник РУдН. Серия Юридические науки. 2012. № 4. С. 117-122. 
4. Давыдов П.М., Якимов П.П. Применение мер процессуального принуждения по основам уголовного судопроизводства СССР и ССР. Свердловск: Изд-во Свердл. юрид. ин-та им. А.Я. Вышинского. 1961. 118 с.

5. Кашкин С.Ю. Хартия Европейского Союза об основных правах: комментарий. М.: Юриспруденция, 2001. 203 с.

6. Кожевников С.Н. Государственное принуждение: особенности и содержание // Советское государство и право. 1978. № 5. С. 47-53.

7. Кокорева Л.В. Процессуальное значение оснований и цели применения мер пресечения в уголовном судопроизводстве // Вестник экономической безопасности. 2016. № 1. С. 103-107.

8. Колоколов Н.А. Судебный контроль в стадии предварительного расследования: учебное пособие. М.: ЮНИТИ-ДАНА, Закон и право, 2004. 303 с.

9. Корнуков В.М. Меры процессуального принуждения в уголовном судопроизводстве. Саратов: Изд-во Саратовского университета, 1978. 137 с.

10. Куликов М.А. Основания применения мер пресечения в России и зарубежных государствах // Вестник Московского университета МВД России. 2020. С. 147-151.

11. Михайлов В.А. Меры пресечения в уголовном судопроизводстве: авторефер. дисс. ... д-ра юрид. наук. М., 1996. 47 с.

12. 0 практике применения судами законодательства о мерах пресечения в виде заключения под стражу, домашнего ареста и залога : постановление пленума Верховного суда Российской Федерации от 19.12.2013 № 41 (ред. от 11.06.2020) // СПС «КонсультантПлюс».

13. Петрухин И.Л. Свобода личности и уголовно-процессуальное принуждение: Общ. концепция. Неприкосновенность личности. М.: Наука, 1985. 239 с

14. Тихомирова Л.В., Тихомиров М.Ю. Юридическая энциклопедия. М.; Изд-во Тихомиров М.Ю., 2004. 972 с.

๑ Ахметгалеев Вадим Ралифович (vahmetgaleev@yandex.ru).

Журнал «Современная наука: актуальные проблемы теории и практики»

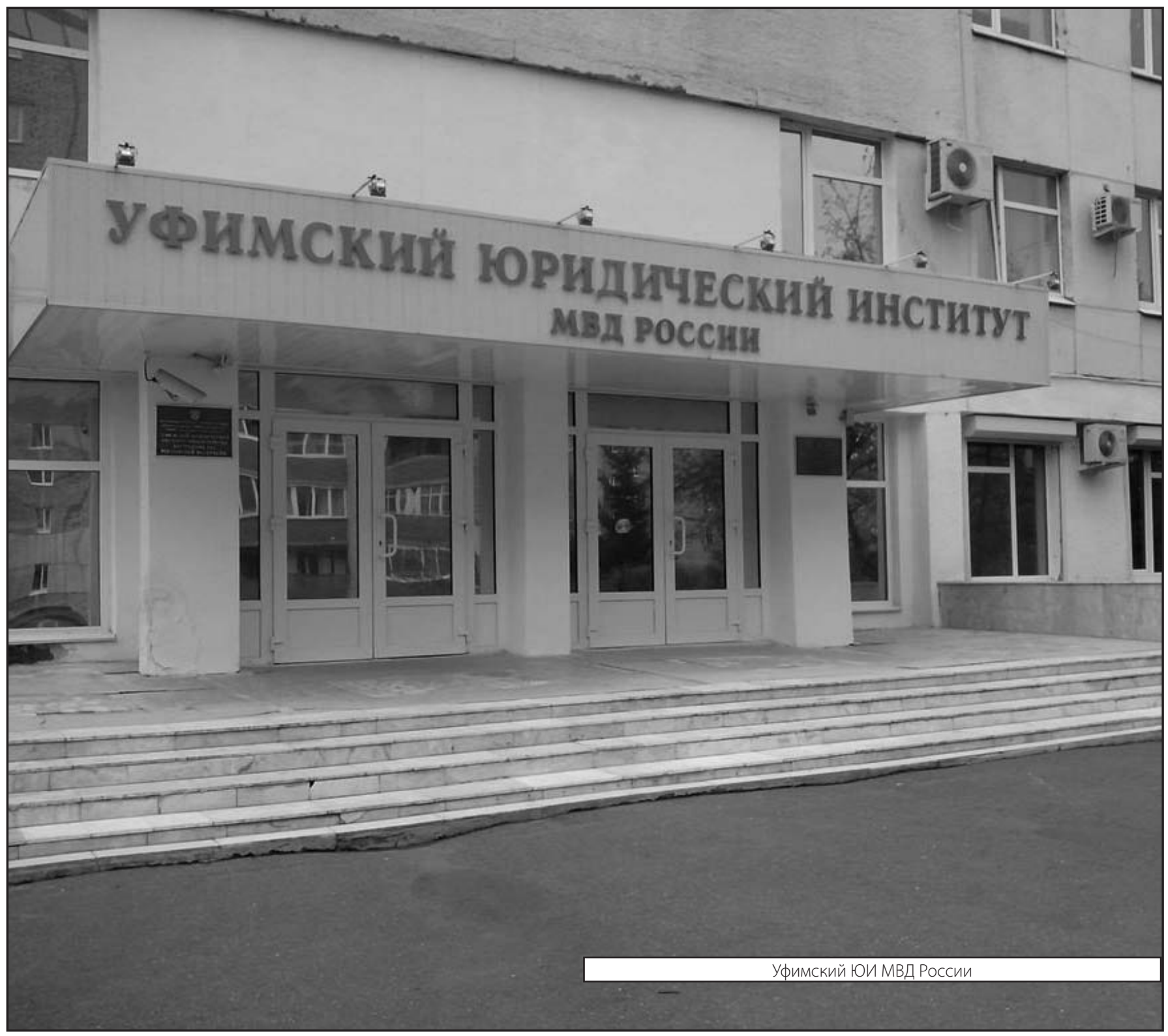

